\title{
Dexketoprofen trometamol-loaded poly-lactic-co-glycolic acid (PLGA) nanoparticles: Preparation, in vitro characterization and cyctotoxity
}

\author{
A. Alper Öztürk ${ }^{1,2 \star}$, Lucia Martin Banderas ${ }^{2}$, Maria D. Cayero Otero ${ }^{2}$, Evrim \\ Yenilmez ${ }^{1}$, Behiye Şenel ${ }^{3}$, Yasemin Yazan ${ }^{1}$ \\ ${ }^{1}$ Department of Pharmaceutical Technology, Faculty of Pharmacy, Anadolu University, Eskişehir, Turkey, ${ }^{2}$ Department of \\ Pharmacy and Pharmaceutical Technology, Faculty of Pharmacy, University of Seville, Seville, Spain, ${ }^{3}$ Department of \\ Pharmaceutical Biotechnology, Faculty of Pharmacy, Anadolu University, Eskişehir, Turkey
}

*For correspondence: Email: aaozturk@anadolu.edu.tr; Tel: +9022 3350580 / 3731

Sent for review: 18 July 2018

Revised accepted: 16 November 2018

\begin{abstract}
Purpose: To design, formulate and characterize sustained-release formulations of dexketoprofen trometamol (DT) nanoparticles (NPs)

Methods: Dexketoprofen trometamol (DT)-loaded poly(lactic-co-glycolic acid) (PLGA) NPs were produced by double emulsion-solvent evaporation method. The NPs were variously characterized for drug loading and release, particle profile, as well as by thermal analysis, $x$-ray difraction (XRD), Fourier transform infrared spectroscopy (FTIR) and nuclear magnetic resonance analysis ( $H$-NMR). Furthermore, the NPs were evaluated for cytotoxicity against NIH-3T3 cells by 3-(4,5-dimethylthiazol-2YI)-2,5-diphenyltetrazolium bromide (MTT) assay.

Results: The DT-loaded NPs demonstrated nanostructural characteristics and extended drug release. Particle size was in the range of 243 and $295 \mathrm{~nm}$ which remained unchanged in drug stability testing in simulated gastrointestinal media. Encapsulation efficiency ranged from $49-64 \%$ for all the formulations. Higuchi and Korsmeyer-Peppas were the best-fit release kinetic models for the NPs containing 5 and $10 \% D T$, respectively. The NPs with $10 \% D T$ presented no significant cytotoxicty at the doses and periods studied.

Conclusion: Stable and non-toxic DT NPs with potential for sustained and controlled release of the drug have been successfully developed.
\end{abstract}

Keywords: Dexketoprofen trometamol, Poly-lactic-co-glycolic acid (PLGA), Nanoparticles, Release kinetics, Stability

\begin{abstract}
This is an Open Access article that uses a funding model which does not charge readers or their institutions for access and distributed under the terms of the Creative Commons Attribution License (http://creativecommons.org/licenses/by/4.0) and the Budapest Open Access Initiative (http://www.budapestopenaccessinitiative.org/read), which permit unrestricted use, distribution, and reproduction in any medium, provided the original work is properly credited.

Tropical Journal of Pharmaceutical Research is indexed by Science Citation Index (SciSearch), Scopus, International Pharmaceutical Abstract, Chemical Abstracts, Embase, Index Copernicus, EBSCO, African Index Medicus, JournalSeek, Journal Citation Reports/Science Edition, Directory of Open Access Journals (DOAJ), African Journal Online, Bioline International, Open-J-Gate and Pharmacy Abstracts
\end{abstract}

\section{INTRODUCTION}

The ability to manage and treat pain continues to be one of the most common clinical objectives of practitioners. Pain has a very important effect on the biological, psychological, sociological and economic dispositions of a patient [1]. Nonsteroidal anti-inflammatory drugs (NSAIDs), skeletal muscle relaxants and opioid analgesics are among the most prescribed drugs for pain 
[2]. The NSAIDs block a group of physiological proteins called cyclooxygenase (COX) which are invoved in the production of prostaglandins and thromboxanes responsible for pain and inflammation [3].

Ketoprofen, a member of the arylpropionate group of NSAIDs has well-defined analgesic and anti-inflammatory effects. Racemic ketoprofen is used as an analgesic and anti-inflammatory agent, and it is one of the most potent inhibitors of prostaglandin synthesis in vitro [4]. Dexketoprofen trometamol (DT) was developed as a water-soluble trometamine. It is a rapidlyacting analgesic agent in the treatment of painful musculoskeletal disorders such as back pain and osteoarthritis [5].

Polymeric nanoparticles (PNPs) are being extensively investigated as drug delivery systems worldwide for pharmaceutical applications. They provide modified release of drugs for extended periods of time [6]. The most commonly used biodegradable polymers in the production of polymeric NPs for modified release are polyglycolic acid, polylactic acid and their copolymers, e.g., PLGA (polylactic-co-glycolic acid) [7].

Modified drug release can be obtained by polymeric NPs owing to different properties of PLGA used [8]. Polyglycolic acid is a hydrophilic agent and dissolves readily in intracellular conditions. Polylactic acid is more hydrophobic than polyglycolic acid due to an additional methyl group in the side chain; and therefore biodegradation takes place much longer than polyglycolic acid [9]. Double emulsion techniques are commonly used for the encapsulation of hydrophilic molecules with low encapsulation efficiency because of rapid drug partitioning into the external aqueous phase in classical emulsions. In double emulsification technique, displacement of a lipophilic solvent with a watermiscible semi-polar solvent results in accumulation of polymer on the surface. Rapid diffusion of the non-solvent reduces the interfacial tension between the two phases leading to an increase in surface area and thus formation of small organic solvent droplets. It is a very simple and economic method [10]. Surveying extant patents and publications, some modified release formulations and locally available commercial preparations of DT were found [11-13].

The present study was carried out to design, formulate and characterize sustained-release formulations of DT NPs.

\section{EXPERIMENTAL}

\section{Chemicals}

Dexketoprofen trometamol was a kind gift from Abdi İbrahim (İstanbul/Turkey). Poly(lactic-coglycolic acid) (PLGA) (Resomer ${ }^{\circledR}$ RG $504 \mathrm{H}$ ) was obtained from Evonik Industries (Germany). Polyvinil alcohol (PVA) was purchased from Sigma-Aldrich (St. Louis, MO, USA), while ethyl acetate and sodium acetate trihydrate were obtained from Panreac Química (Barcelona, Spain). Methanol was from Merck (Gradient grade for liquid chromatography, Darmstadt/ Germany). Deionized and filtered water was used in all experiments (Milli-Q Academic, Millipore, Molsheim, France). All other chemicals used were of analytical grade.

\section{Preparation of PLGA nanoparticles}

The PLGA NPs were prepared by 'Double Emulsification Solvent Evaporation Technique' [14]. Weighed amount of PLGA was dissolved in ethyl acetate to obtain a concentration of 40 $\mathrm{mg} / \mathrm{mL}$. Then, $100 \mu \mathrm{L}$ aqueous solution of PVA $(0.5 \% \mathrm{w} / \mathrm{v})$ was added drop-wise to $2 \mathrm{~mL}$ PLGA solution using ultrasonic bath (1 minute, JP Selctra) $\left(\mathrm{W}_{1} / \mathrm{O}\right)$. Two $\mathrm{mL}$ of this emulsion was then added drop-wise to $10 \mathrm{~mL}$ of PVA aqueous solution $(0.5 \%, \quad \mathrm{w} / \mathrm{v})$ using high-speed homogenizer (Polytron PT $2500 \mathrm{E}$ ) at $24.000 \mathrm{rpm}$ for $1 \mathrm{~min}\left(\mathrm{~W}_{1} / \mathrm{O} / \mathrm{W}_{2}\right)$. The ethyl acetate was evaporated at room temperature in $4 \mathrm{~h}$ to obtain an aqueous dispersion which was finally centrifuged to obtain the NPs (11.000 rpm, 30 min, and $4{ }^{\circ} \mathrm{C}$; Eppendorf 504R, Eppendorf AG, Hamburg, Germany). For the preparation of DTloaded PLGA NPs, the procedure was started by adding 4 - $8 \mathrm{mg}$ DT [5 \% DT (Alp-5) and $10 \%$ DT (Alp-10)] to $100 \mu \mathrm{L}$ aqueous solution of PVA (0.5 $\% \mathrm{w} / \mathrm{v})$. The aqueous solution of PVA containing $100 \mu \mathrm{L}$ DT was added drop-wise to $2 \mathrm{~mL}$ PLGA solution in an ultrasonic bath (1 min, JP Selctra) $\left(\mathrm{W}_{1} / \mathrm{O}\right)$. Two $\mathrm{mL}$ of this emulsion was then added drop-wise to $10 \mathrm{~mL}$ of PVA aqueous solution (0.5 $\%$, w/v) under high-speed homogenizer (Polytron PT $2500 \mathrm{E})$ at $24.000 \mathrm{rpm}$ for $1 \mathrm{~min}\left(\mathrm{~W}_{1} / \mathrm{O} / \mathrm{W}_{2}\right)$. The ethyl acetate was evaporated at room temperature in $4 \mathrm{~h}$ to obtain an aqueous dispersion which was finally centrifuged to obtain the NPs $\left(11,000 \mathrm{rpm}, 30 \mathrm{~min}, 4^{\circ} \mathrm{C}\right.$; Eppendorf 504R, Eppendorf AG, Hamburg, Germany).

\section{Determination of particle size, PDI, zeta potential and morphology}

Particle size (PS) and PDI were measured on freshly prepared samples using Malvern analyzer (Zetamaster 3000, Malvern Instruments Ltd., 
UK). Samples of all PLGA NPs were diluted with distilled water prior to analysis. All analyses were repeated three times at room temperature. Surface electrical charge (zeta potential) of PLGA NPs was characterized by laser Doppler electrophoresis (Zetamaster 3000, Malvern Instruments Ltd, UK). Measurements were repeated three times at room temperature. Morphological and structural characteristics of the PLGA NPs prepared were investigated using SEM (Hitachi TM 3030 Plus, Japan). Lyophilized samples were coated with thin layer of gold using a coater (Karaltay Scientific Instruments, China) under $50 \mathrm{~mA}$ for 30 seconds before observation under a scanning electron micoscope (SEM).

\section{Assessment of cryoprotectant effect on PLGA NPs}

Some experiments were carried out on Alp-5 and Alp-10 formulations to determine storage and lyophilization conditions. Following PS measurement of fresh formulations, they were centrifuged and the supernatants were discarded. The resulting particles were added to $1 \mathrm{~mL}$ of $5 \%(\mathrm{w} / \mathrm{v})$ trehalose solution and the PS measurement was performed again. The dispersion was then divided into 10 equal portions in 10 eppendorf tubes numbered $1-10$. While no trehalose solution was added to tubes 1 and 2, $100 \mu \mathrm{L}, 200 \mu \mathrm{L}, 300 \mu \mathrm{L}$ and $400 \mu \mathrm{L}$ trehalose solution $(5 \% \mathrm{w} / \mathrm{v})$ were added to tubes 3 and $4 ; 5$ and $6 ; 7$ and 8; 9 and 10 , respectively (i.e. in duplicates). All formulations were then frozen at $-20^{\circ} \mathrm{C}$ prior to PS analysis after melting tubes $1,3,5,7$ and 9 at room temperature. Following lyophilization $\left(\right.$ Telstar $^{\circledR}$ CRYODOS, Liofilizador de Laboratorio, Spain) of tubes 2, 4, 6,8 and 10, the dry particles were removed from the lyophilizer and dispersed in $1 \mathrm{~mL}$ of water, followed by PS analysis.

\section{Evaluation of stability of PLGA NPs}

The NPs prepared using hydrolytic degradable polymers are known to degrade over time. Effects of $\mathrm{pH}$ and temperature have a very significant effect on long-term stability [15]. Before testing the stability of PLGA NPs, solutions simulating gastrointestinal fluids were prepared. The solutions were pepsin-free $\mathrm{HCl}$ $(\mathrm{pH}$ 1.2, Solution 1), pepsin-containing $\mathrm{HCl}$ solution ( $\mathrm{pH} 1.2$, Solution $2,0.32 \%$ pepsin, w/v); intestinal fluid phosphate buffer solution (Solution 3 , pH 6.8); phosphate buffer solution (Solution 4, $\mathrm{pH}$ 7.4); physiological serum $(0.9 \% \mathrm{NaCl})$ solution (Solution 5) and Milli-Q water.

All five solutions and Milli-Q water were placed in a shaking water bath at a stirring speed of 40 rpm at a temperature of $37 \stackrel{\circ}{\circ}$ to simulate the gastric medium. One set of formulations (Alp-5 and Alp-10) was prepared and dispersed in trehalose solution at $5 \%(\mathrm{w} / \mathrm{v})$ concentration. Then, $1 \mathrm{~mL}$ of this dispersion was added to solutions incubated at $37 \pm 1^{\circ} \mathrm{C}$. Samples were collected after preincubation periods of $1,2,3,4$, $5,6,7$ and $24 \mathrm{~h}$ and centrifuged at $4.000 \mathrm{rpm}$ for 5 min to precipitate NPs. Finally, the average particle size of the NPs was determined with laser scattering.

\section{HPLC conditions}

The amount of DT loaded into PLGA NPs and dissolution study of each formulation was performed using HPLC (Shimadzu Corporation, Kyoto, Japan) with reversed-phase Symetry ${ }^{\circledR}$ and C18 (5.0 $\mu \mathrm{m}, 250 \mathrm{~mm} \times 4.6 \mathrm{~mm}$, Symmetry US) column. In the HPLC system, the mobile phase was methanol:acetate buffer $(65: 35 \mathrm{v} / \mathrm{v})$ mixture, the flow rate was $0.9 \mathrm{~mL} \cdot \mathrm{min}^{-1}$, while detection was performed at $242 \mathrm{~nm}$ at $40^{\circ} \mathrm{C}$. Injection volume and run time were $25 \mu \mathrm{L}$ and $12 \mathrm{~min}$, respectively. Mobile phase was prepared daily, de-gassed by sonication and filtered through $0.45 \mu \mathrm{m}$ membrane filter before the experiment. The method was validated for precision, accuracy, specificity and linearity [16].

\section{Evaluation of entrapment efficiency}

The loading of DT into PLGA NPs was determined by reverse phase-HPLC (RP-HPLC) method as described earlier. The DT content of PLGA NPs was assessed directly by extracting DT from NPs. Lyophilized NPs (about $5 \mathrm{mg}$ ) were weighed, $1 \mathrm{~mL}$ ethyl acetate was added and the mixture was vortexed to dissolve the particles in the organic phase. All solutions were filtered through $0.22 \mu \mathrm{m}$ polyamid filter prior to analysis with HPLC system. The DT content was expressed as encapsulation efficiency (EE) as in Eq 1.

$\mathrm{EE}(\%)=\left\{\left(\mathrm{W}_{1}-\mathrm{W}_{2}\right) / \mathrm{W}_{1}\right\} 100 \ldots \ldots \ldots .(1)$

where W1 is the actual amount of DT loaded into PLGA NPs and W2 is the theoretical amount of DT loaded into PLGA NPs.

\section{In vitro dissolution studies}

The ability of the PLGA formulations to release DT in the stomach (pH 1 or 1.2), small intestine $(\mathrm{pH}$ 6.8) and colon ( $\mathrm{pH}$ 7.4) was assessed by release studies in simulated gastric and intestinal media [17]. In vitro release profiles from PLGA NPs were investigated over 10 days using a dialysis membrane. PLGA NPs equivalent to 10 
mg DT was placed in a cellulose acetate dialysis bag with a molecular weight of 12-14 kDa (Sigma). After sealing the two ends, in vitro release study was started in $75 \mathrm{~mL} 0.1 \mathrm{~N}$ hydrochloric acid ( $\mathrm{pH} 1.0)$ at $37^{\circ} \mathrm{C}$ with stirring at 100 rpm using a magnetic stirrer.

The study was carried out for $2 \mathrm{~h}$, and then continued at $\mathrm{pH} 6.8$ (obtained by addition of 25 $\mathrm{mL} 0.2 \mathrm{M}$ tribasic sodium phosphate solution) for the next $3 \mathrm{~h}$, and thereafter at $\mathrm{pH} 7.4$ (obtained by addition of $5 \mathrm{~mL} 0.2 \mathrm{M}$ tribasic sodium phosphate solution) for the remaining time intervals. Stirring was maintained at $100 \mathrm{rpm}$ and temperature at $37 \pm 0.5^{\circ} \mathrm{C}$ in all media. Samples were collected at certain intervals and replaced with the same volume of fresh dissolution medium. The samples were then analyzed using HPLC method.

\section{Determination of in vitro release kinetics}

Data obtained in the in vitro drug release studies were further investigated for release kinetics using DDSolver software program [18].

\section{Thermal analysis}

Thermal analysis of the NPs prepared was carried out using DSC (Schimadzu DSC-60, Japan) in a pressure-assisted aluminum sample vessel at a nitrogen gas flow rate of $50 \mathrm{~mL} \cdot \mathrm{min}^{-1}$ and a temperature increase rate of $10^{\circ} \mathrm{C} \cdot \mathrm{min}^{-1}$ at $50-250^{\circ} \mathrm{C}$ with aluminum reference.

\section{XRD analysis}

The NPs were subjected to XRD analysis performed with a Rikagu generator (XRD Rikagu Rint 2000, Japan) at a speed of $40 \mathrm{kV}$, current intensity of $30 \mathrm{~mA}$, angle of $2^{\ominus}$ and speed of $1^{\circ} \cdot \mathrm{min}^{-1}$ in the range of $5^{\circ}-45^{\circ}$.

\section{FT-IR analysis}

The FT-IR spectra of the NPs prepared were determined by FT-IR (Schimadzu IR Prestige-21, Japan) in the wavelength range of $4000^{-1}$ and $500 \mathrm{~cm}^{-1}$.

\section{${ }^{1} \mathrm{H}-\mathrm{NMR}$ analysis}

The PLGA NPs were subjected to NMR analysis ( $\left.{ }^{1} \mathrm{H}-\mathrm{NMR}\right)$. They were collected by centrifugation, lyophilized and dissolved in deutero chloroform $\left(\mathrm{CDCl}_{3}\right)$ prior to analysis using NMR (Bruker 500 $\mathrm{MHz}$ UltraShield NMR, Germany).

\section{Cell culture}

Mouse embryonic fibroblast cells (NIH/3T3) were selected for culture studies. The cells were grown in Dulbecco's Modified Eagle's Medium (DMEM) supplemented with $10 \%$ fetal bovine serum (Sigma Aldrich, Germany), $2 \mathrm{mM} \mathrm{L-}$ glutamine and penicillin-streptomycin (Sigma Aldrich, Germany) at $37^{\circ} \mathrm{C}$ in a humidified atmosphere containing $5 \% \mathrm{CO}_{2}$.

\section{Cytotoxicity studies}

Quantitative cell cytotoxicity was determined by colorimetric MTT (3-(4, 5-dimethyl thiazol-2yl)-2, 5-diphenyl tetrazolium bromide) assay. Briefly, cells removed from the flask were seeded in 96well plates and left to incubate for $24 \mathrm{~h}$. At the end of the incubation period, fresh growth media containing different concentrations of NPs were added to the wells to give final concentrations in the range $5-1000 \mu \mathrm{g} / \mathrm{mL}$. The plates were reincubated for another 24 - $48 \mathrm{~h}$, and MTT dye was added at end of each incubation time. The resultant formazan crystals were dissolved with DMSO, and the absorbance of solution was read at $572 \mathrm{~nm}$ in a microplate reader (BioTek Cytation5, Germany) [19]. The results obtained were expressed as percentage inhibition relative to control cells where cell survival was taken as $100 \%$. The experiments were performed in triplicate.

\section{Statistical analysis}

Each experiment was carried out three independent times and the data are presented as mean \pm standard deviation (SD). Microsoft Excel and DDSolver were employed for statistical analysis.

\section{RESULTS}

Particle size, polydispersity index and zeta potential

The size and size distribution of PLGA NPs measured by laser scattering method are presented in Table 1. All data obtained from six independent experiments were expressed as the mean diameter and standard deviation (SD) values. Figure 1 shows SEM images of the prepared PLGA NPs. The images revealed regular and symmetrical morphology.

\section{Effect of cryoprotectant on PLGA NPs}

Figure 2 shows the effect of cryoprotectant addition on Alp-5 and Alp-10 NP sizes and size distributions. 
Table 1: Particle size, PDI, zeta potential and entrapment efficiency of DT nanoparticles (mean \pm SD)

\begin{tabular}{lcccc}
\hline Code & PS $(\mathbf{n m})$ & PDI & ZP $(\mathbf{m V})$ & EE \% \pm SD \\
\hline Alp-blank & $295.7 \pm 2.9$ & $0.101 \pm 0.015$ & $-29.59 \pm 0.23$ & - \\
Alp-5 & $243.8 \pm 5.3$ & $0.062 \pm 0.024$ & $-27.26 \pm 0.92$ & $64.194 \pm 0.484$ \\
Alp-10 & $251.9 \pm 2.8$ & $0.075 \pm 0.020$ & $-26.48 \pm 0.63$ & $49.239 \pm 1.129$ \\
\hline
\end{tabular}

PS: particle size, PDI: polydispersity index, ZP: zeta potential, EE: entrapment efficiency, SD: standard deviation

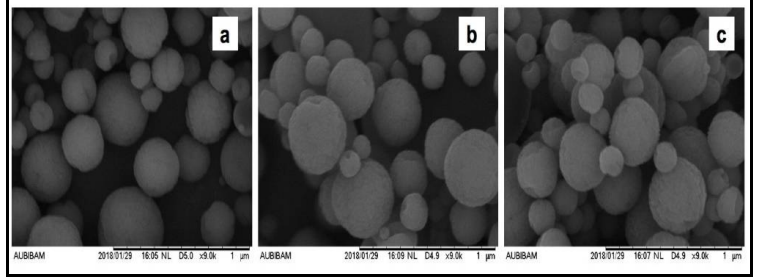

Figure 1: Scanning electron micrographs of PLGA NPs. a: Alp-blank, b: Alp-5, c: Alp-10

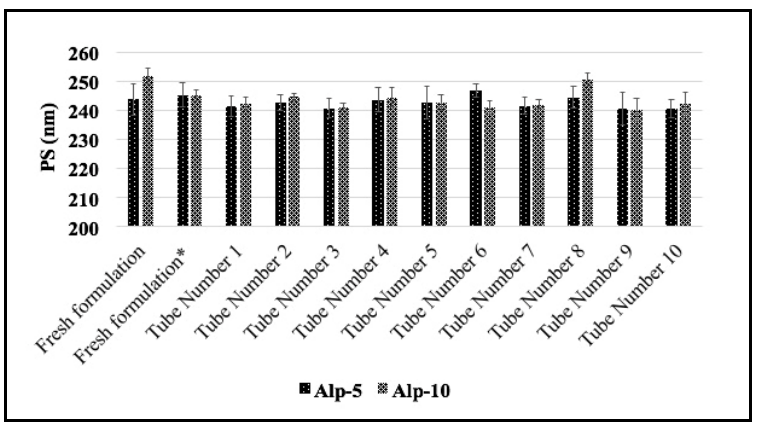

Figure 2: Effect of cryoprotectant on particle size distribution of nanoparticles prepared. PS: Particle size; *: fresh formulation after centrifugation and dispersing in $1 \mathrm{~mL}$ trehalose solution ( $5 \% \mathrm{w} / \mathrm{v})$

\section{Stability of PLGA NPs}

Figure 3 shows NP sizes in MilliQ water, pepsinfree $\mathrm{HCl}$ solution, $\mathrm{pH} 1.2$; , pepsin-containing $\mathrm{HCl}$ solution, $\mathrm{pH} 1.2$; intestinal fluid phosphate

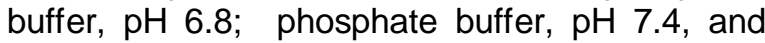
physiological serum $(0.9 \% \mathrm{NaCl})$.

\section{Drug content}

The HPLC method used in the study was validated for precision, accuracy, specificity and linearity. Linearity was at a concentration range of 9.375 - $250 \mu \mathrm{g} \cdot \mathrm{mL}^{-1}$. The method for DT was precise due to RSD values of $<2 \%$ for repeatability and intermediate precision. Recovery of the method was satisfactory owing to $<2 \%$ RSD value. The DT showed a linearity of $\mathrm{y}=17901 \mathrm{x}+1890.4\left(\mathrm{r}^{2}=0.999\right)$, and accuracy of $100.103 \pm 0.203,100.094 \pm 0.123$ and $99.658 \pm 0.521 \%$ for 25,100 and 150 $\mu \mathrm{g} \cdot \mathrm{mL}^{-1}$, respectively $(\mathrm{n}=6)$. The limit of detection (LOD) was $0.0002 \mu \mathrm{g} \cdot \mathrm{mL}^{-1}$, while the limit of quantitation (LOQ) was $0.0006 \mu \mathrm{g} \cdot \mathrm{mL}^{-1}$.

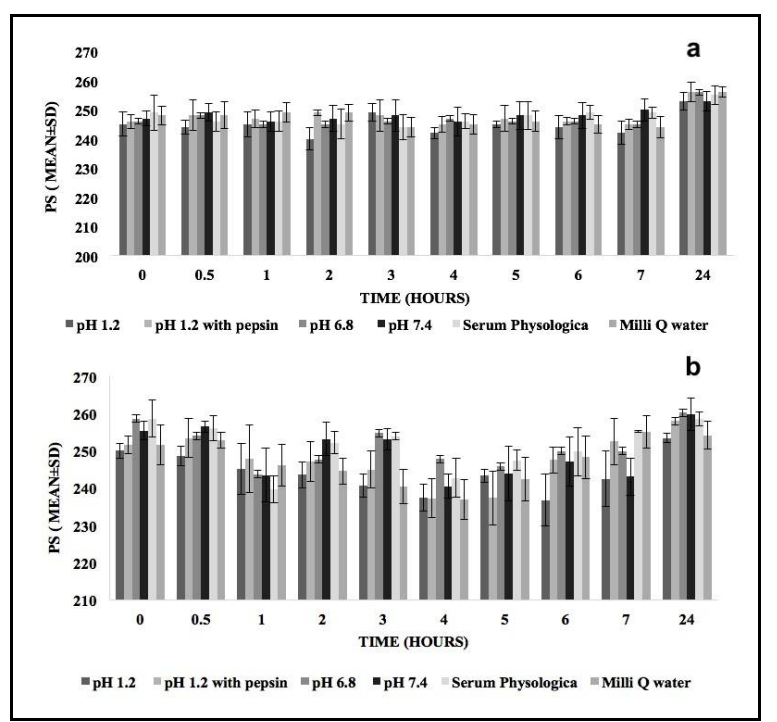

Figure 3: Stability test in different media, a: Alp-5, b Alp-10, PS: nm range

\section{Entrapment efficiency (EE)}

The EE \% values of NPs loaded with DT are given in Table 1.

\section{In vitro dissolution}

The DT release profiles from PLGA NPs are shown in Figure 4. The release of DT continued over 10 days while pure DT exhibited a rapid release of $99.087 \%$ in 1 day. The release values observed from Alp-5 and Alp-10 formulations after 10 days were $75.976 \%$ and $92.156 \%$, respectively, demonstrating modified release from both formulations, relative to pure DT.

\section{In vitro release kinetics}

Kinetic modeling of DT release from PLGA NPs is shown in Table 2. In this study, DDSolver computer program was used to shorten the calculation time, eliminate calculation errors and determine the correct release profile. After obtaining the release profiles, data were transferred to the DDSolver program to determine the four most important and popular criteria: coefficient of determination (Rsqr, $\mathrm{R}^{2}$, or COD), adjusted coefficient of determination

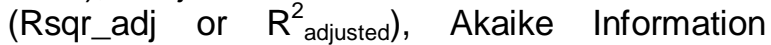
Criterion (AIC) and Model Selection Criterion (MSC). The highest $R^{2}, R^{2}$ adjusted and MSC values 
and the lowest AIC values were used for evaluating zero-order kinetics, first-order kinetics, Higuchi, and Korsmeyer-Peppas models [18]. The $R^{2}, R_{\text {adjusted, }}^{2}$ MSC and AIC obtained are shown in Table 3.

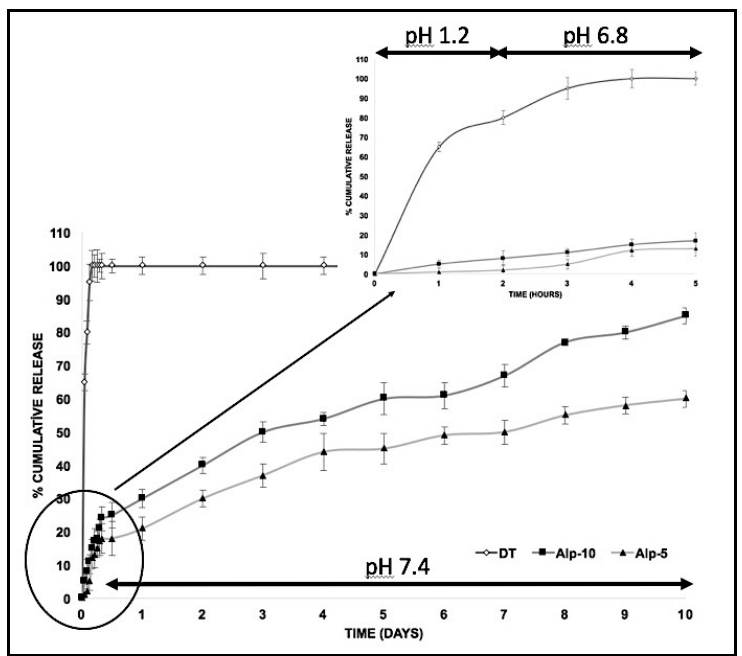

Figure 4: In vitro dissolution profiles of pure DT and DT from nanoparticles prepared

\section{Thermograms}

Thermal analysis (DSC) results of pure DT, Alpblank, Alp-5 and Alp-10 PLGA NPs obtained in the determination of the physical state of DT in NPs are given in Figure 5. The melting endothermic peak of pure DT which appeared at $105.1^{\circ} \mathrm{C}$ disappeared in thermograms of Alp-5 and Alp-10 formulations.

Table 3: Kinetic release data

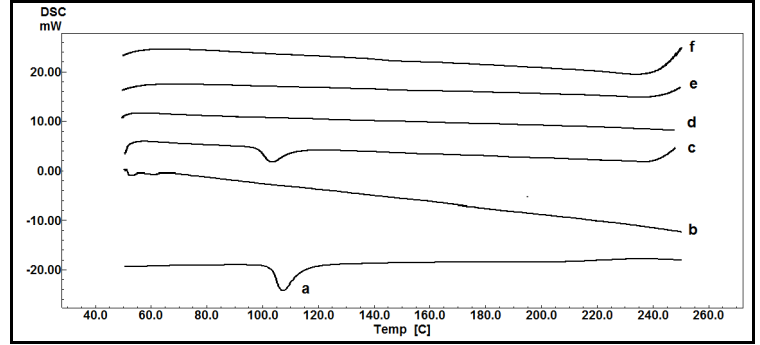

Figure 5: Thermogram of a: pure DT, b: PLGA, c: Physical mixture, d: Alp-blank, e: Alp-5, f: Alp-10

\section{XRD analysis}

The XRD profiles of pure DT, pure polymers, physical mixture and the formulations prepared are given in Figure 6 . The XRD profiles of all prepared NPs had no DT crystal peaks. In contrast, there were DT peaks in the physical mixture

\section{FT-IR spectra}

The FT-IR analysis results are shown in Figure 7. The IR spectrum of PLGA polymer exhibited molecular vibrations of its different functional groups as shown in Figure 8. Carbonyl groups observed between $1770 \mathrm{~cm}^{-1}$ and $1750 \mathrm{~cm}^{-1}$ with intense bands may be attributed to the stretching vibration of the carbonyl groups present in the two monomers.

Medium intensity bands between $1300 \mathrm{~cm}^{-1}$ and $1150 \mathrm{~cm}^{-1}$ show asymmetric and symmetric C$\mathrm{C}(=\mathrm{O})-\mathrm{O}$ streches, respectively, which are distinctive bands often used for the characteriza-

\begin{tabular}{|c|c|c|c|c|c|}
\hline \multirow{2}{*}{ Formulation } & \multirow{2}{*}{ Model and equation } & \multicolumn{4}{|c|}{ Evaluation criteria } \\
\hline & & $\mathbf{R}^{2}$ & $\mathbf{R}_{\text {adjusted }}^{2}$ & AIC & MSC \\
\hline Alp-5 & $\begin{array}{l}\text { Zero-order model } \\
\mathrm{F}=\mathrm{k}_{0}{ }^{*} \mathrm{t}\end{array}$ & 0.696 & 0.696 & 149.253 & 1.019 \\
\hline Alp-10 & $\begin{array}{l}\text { Zero-order model } \\
\mathrm{F}=\mathrm{k}_{0}{ }^{*} \mathrm{t}\end{array}$ & 0.675 & 0.675 & 158.618 & 1.087 \\
\hline Alp-5 & $\begin{array}{l}\text { First-order model }{ }^{*} \\
F=100^{*}\left[1-\operatorname{Exp}\left(-k_{1}{ }^{*} t\right)\right]\end{array}$ & 0.793 & 0.793 & 140.688 & 1.470 \\
\hline Alp-10 & $\begin{array}{l}\text { First-order model }{ }^{*} \\
F=100^{*}\left[1-\operatorname{Exp}\left(-k_{1}{ }^{*} t\right)\right]\end{array}$ & 0.850 & 0.850 & 145.222 & 1.792 \\
\hline Alp-5 & $\begin{array}{l}\text { Higuchi model }{ }^{*} \\
\mathrm{~F}=\mathrm{k}_{\mathrm{H}^{*}} \mathrm{t}^{0.5}\end{array}$ & 0.968 & 0.968 & 105.219 & 3.336 \\
\hline Alp-10 & $\begin{array}{l}\text { Higuchi model } \\
\mathrm{F}=\mathrm{k}_{\mathrm{H}}{ }^{*} \mathrm{t}^{0.5}\end{array}$ & 0.978 & 0.978 & 108.897 & 3.704 \\
\hline Alp-5 & $\begin{array}{l}\text { Korsmeyer-Peppas* Model } \\
F=k_{K P}{ }^{*} t^{n}\end{array}$ & 0.922 & 0.917 & 101.942 & 2.338 \\
\hline Alp-10 & $\begin{array}{l}\text { Korsmeyer-Peppas* Model } \\
F=k_{K P}{ }^{*} t^{n}\end{array}$ & 0.986 & 0.985 & 124.182 & 4.070 \\
\hline
\end{tabular}

${ }^{*} \mathbf{F}$ : fraction (\%) of drug released in time $\mathbf{t}, \mathbf{k}_{\mathbf{0}}$ : zero-order release constant, $\mathbf{k}_{\mathbf{1}}$ : first-order release constant, $\mathbf{k}_{\mathbf{H}}$ : Higuchi release constant, $\mathbf{k}_{\mathrm{KP}}$ : release constant incorporating structural and geometric characteristics of drugdosage form, $\mathbf{n}$ : diffusional exponent indicating drug-release mechanism 


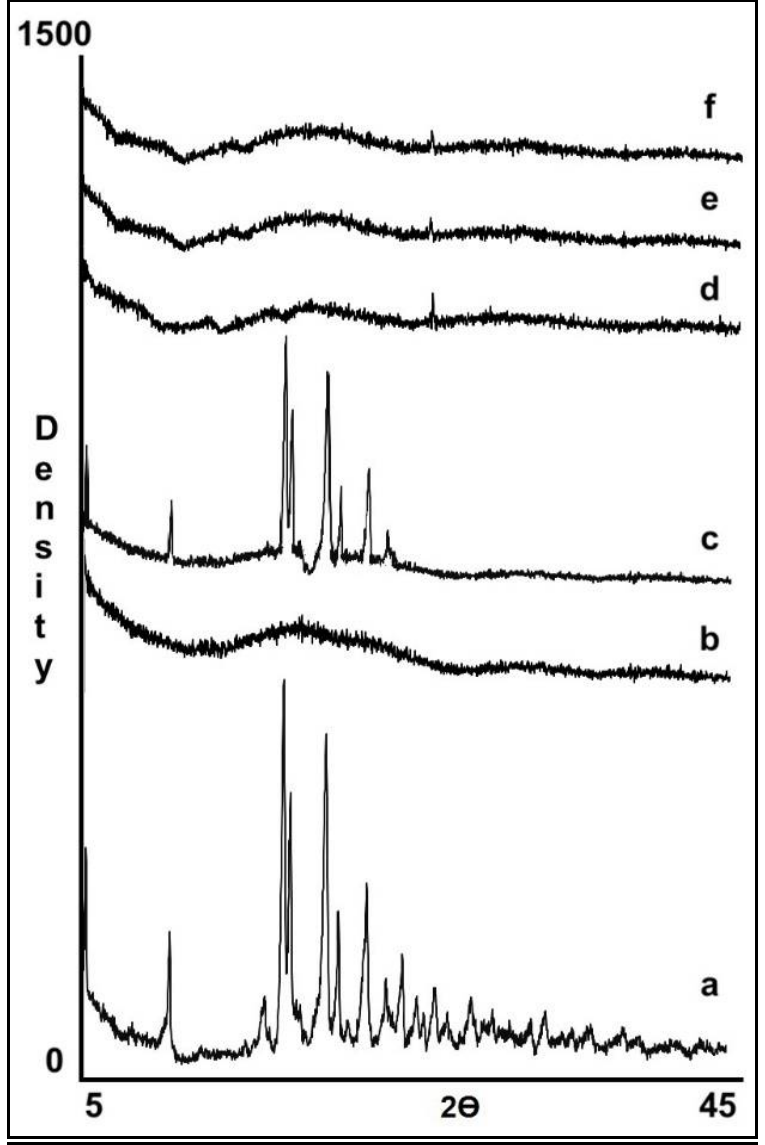

Figure 6: X-ray diffractograms of a: DT, b: PLGA, c: physical mixture, d: Alp-blank, e: Alp-5, f: Alp-10

tion of esters. Stretching vibrations of the $\mathrm{OH}$ group at $3500 \mathrm{~cm}^{-1}$ and $3450 \mathrm{~cm}^{-1}$ refer to lactides and glycolides. According to the literature, DT is characterized by an intense band at $1020 \mathrm{~cm}^{-1}$. Vibrations at $1571 \mathrm{~cm}^{-1}, 1536$ $\mathrm{cm}^{-1}, 1020 \mathrm{~cm}^{-1}, 881 \mathrm{~cm}^{-1}, 771 \mathrm{~cm}^{-1}$ and 641 $\mathrm{cm}^{-1}$ indicate the purity of DT [20].

\section{NMR spectra}

The ${ }^{1} \mathrm{H}-\mathrm{NMR}$ spectra of pure DT, pure PLGA $\left(\right.$ Resomer $^{\circledR} 504 \mathrm{H}$ ) and blankempty/loaded PLGA NPs are shown in Figure 8. It is known that PLGA (Resomer ${ }^{\circledR}$ RG 504H) contains two types of structural units: the most intense signals of $\mathrm{CH}$ (5.16 ppm) and $\mathrm{CH}_{3}$ (1.44 ppm) from lactic acid and $\mathrm{CH}_{2}$ (4.88 ppm) from glycolic acid. The $\mathrm{CH}_{2}$ hydrogens were diastrotopic and divided into two, ending in two pairs of peaks which were assigned for both protons. Higher $\mathrm{CH}_{2}, \mathrm{CH}_{3}$ and $\mathrm{CH}$ signals in the copolymer caused those peaks to expand. Specific peaks of DT in ${ }^{1} \mathrm{H}-\mathrm{NMR}$ spectrum were observed at $1.45(\mathrm{~d}, 3 \mathrm{H}) \mathrm{ppm}$, $3.64(\mathrm{~s}, 6 \mathrm{H}) \mathrm{ppm}, 3.66(\mathrm{q}, 1 \mathrm{lH}) \mathrm{ppm}$ and 7.41$7.80(\mathrm{~m}, 9 \mathrm{H}) \mathrm{ppm}[13]$.

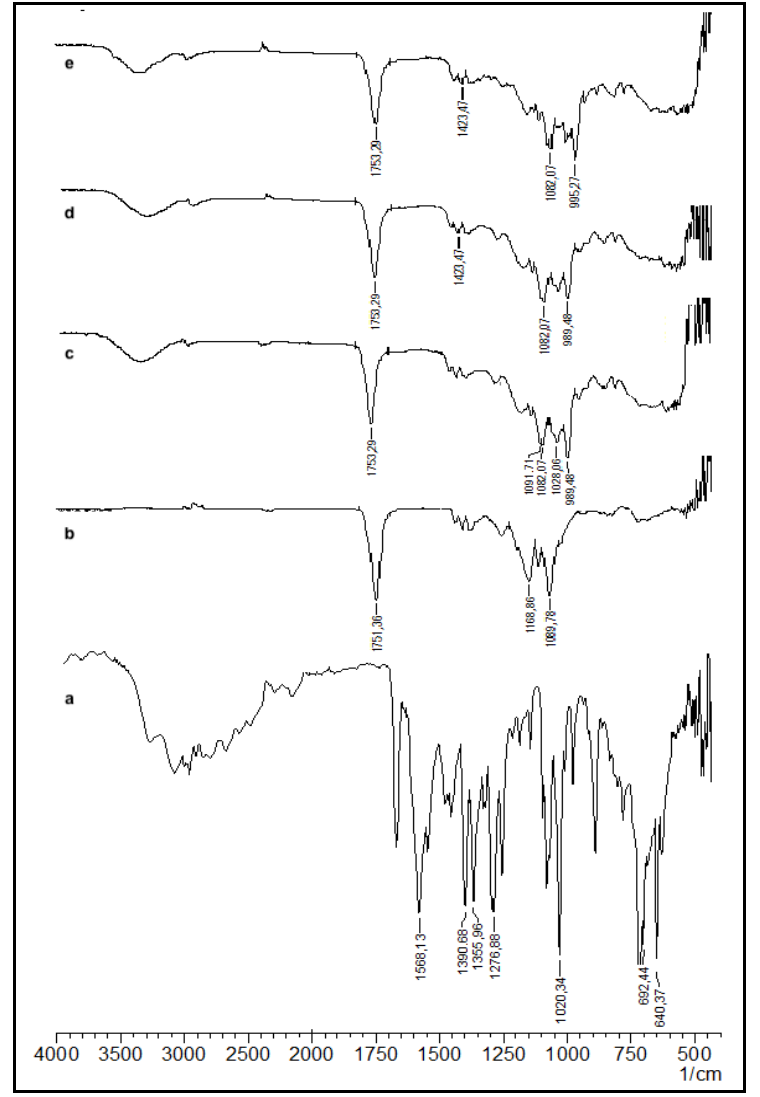

Figure 7: FTIR spectra of, a: DT, b: PLGA, c: Alpblank, d: Alp-5, e: Alp-10

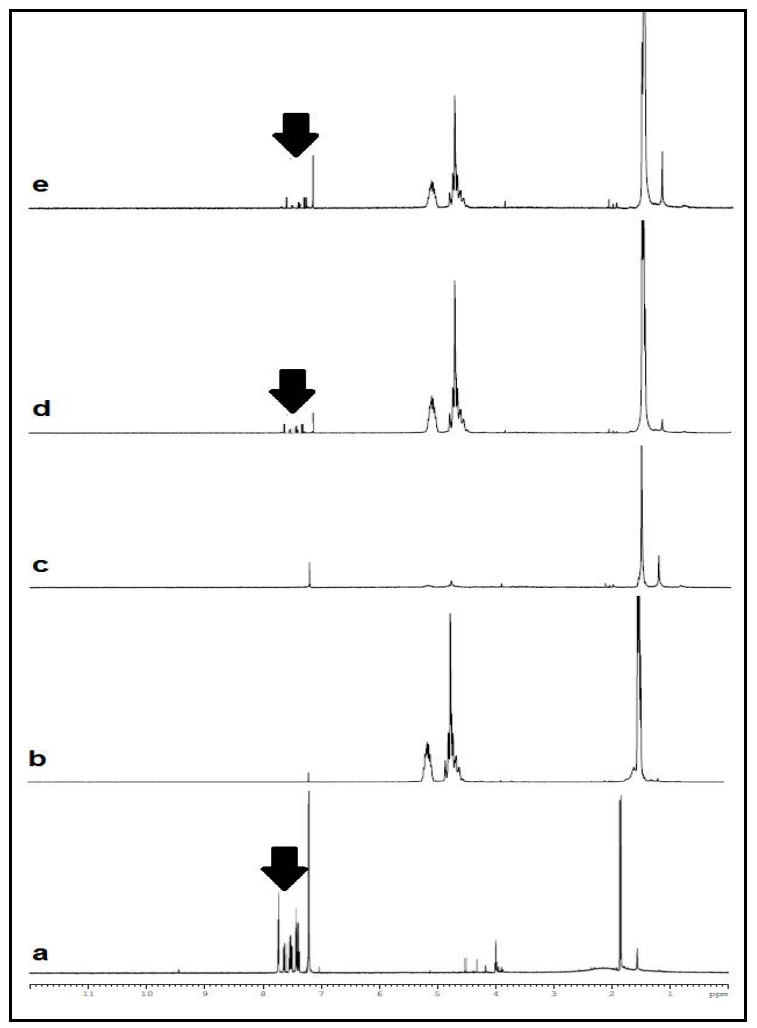

Figure 8. ${ }^{1} \mathrm{H}-\mathrm{NMR}$ spectra of a: DT, b: PLGA, c: Alpempty, d: Alp-5, and e: Alp-10 


\section{Cytotoxicity of nanoparticles}

In vitro cytotoxicity testing is important in assessing biocompatibility of new formulations to ensure absence of acute toxicity response or risk for patients. The cell viabilities at various DT concentrations are shown in Figure 9. From the results obtained, the $\mathrm{IC}_{50}$ values in wells treated with DT only were $750 \mu \mathrm{g} / \mathrm{mL}$ and $250 \mu \mathrm{g} / \mathrm{mL}$ at 24 and $48 \mathrm{~h}$, respectively. Alp-blank did not reduce cell viability below $88 \%$ even at the highest dose applied. Alp-10 formulation showed 69 and $55 \%$ cell viabilities after 24 and $48 \mathrm{~h}$, respectively, when the highest dose was applied.

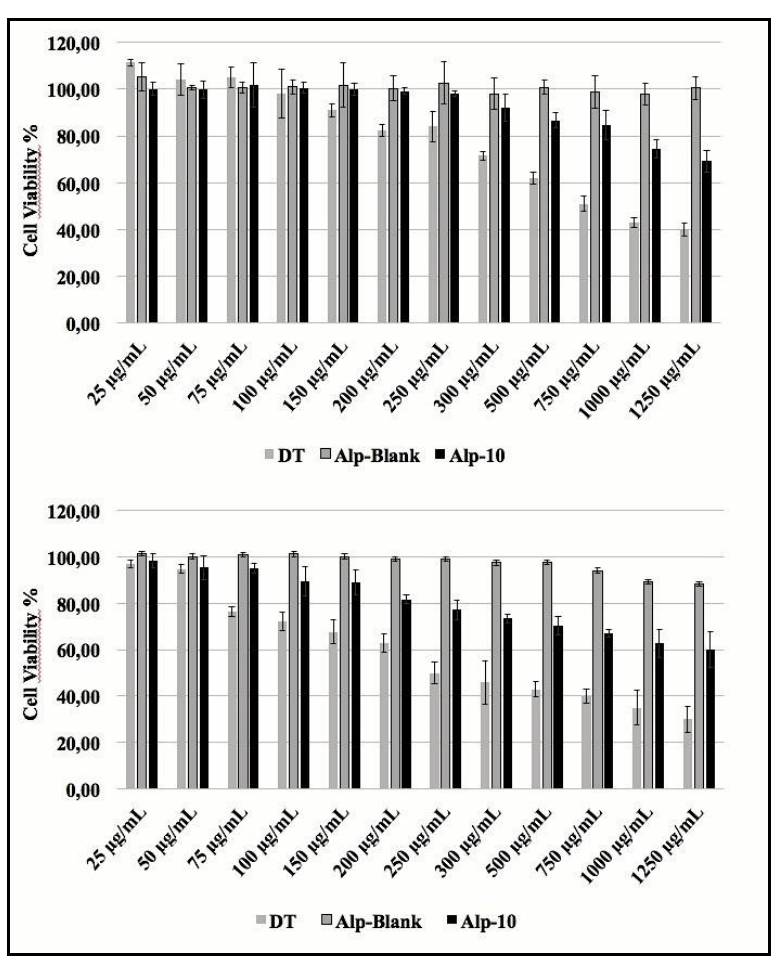

Figure 9: Cell viability of PLGA NP formulations prepared (24 hours and 48 hours from top to bottom, respectively)

\section{DISCUSSION}

Nanosized particles determined with 243.8 $295.7 \mathrm{~nm}$ sizes can be attributed to the hydrophobicity of the polymer used. Small particle sizes were obtained using polymers with high molecular weight and high hydrophobicity due to longer aliphatic chains. It is also known that low particle sizes are obtained as a result of preparation conditions (24.000 rpm, $1 \mathrm{~min}$ ) [21]. The $10 \%$ DT-incorporated particles appeared to have bigger sizes when compared to other DTloaded particles.

Polydispersity index (PDI) indicates the range of particle size distribution, and PDI values in the range of $0-1$ demonstrate homogeneous distribution when it approaches zero. Very low PDI values of prepared formulation indicate homogeneous particle size distribution $[13,20]$. Zeta potential (ZP) values of PLGA NPs were found to be negative most probably due to the total negative charges of the functional groups on PLGA. Studies have shown that NPs with a ZP value of about $+/-30 \mathrm{mV}$ are stable in suspension due to prevention of particles from accumulating [20].

Freeze-drying (lyophilization) is a popular and preferred procedure for increasing the stability of various pharmaceutical products [14]. Since NPs may increase in size during freezing and drying steps, special agents must be added to the suspension before freezing to protect them. The most popular cryoprotectants for freeze-dried NPs are sugar derivatives, eg trehalose, sucrose, glucose and mannitol [20]. In this study, trehalose was used at different concentrations and the sizes of nanoparticles were measured after freezing in the refrigerator to determine the optimum concentration of the cryoprotectant. Usually, the level of cryoprotectant used ranges from 0 to $50 \%$ by weight, which is solubilized directly in NPs suspension immediately prior to freeze-drying [14]. Particle sizes seem to be similar for all trehalose concentrations. The NP size was increased at low concentration of trehalose and therefore $1 \mathrm{~mL}$ trehalose solution was found to be adequate for keeping the particle size constant after freeze-drying.

The stability of NPs was tested at $37^{\circ} \mathrm{C}$ in different media for better understanding of in vitro release profiles. After incubation for $24 \mathrm{~h}$ at $37^{\circ} \mathrm{C}$ in MilliQ water and all other solutions, average sizes of NPs did not change significantly, when compared to the first particle size measured. The results obtained indicate slow degradation of NPs in all media at $37^{\circ} \mathrm{C}$, which also provides preliminary information for selection of dissolution medium [14].

Drug loading capacity of NPs is an important factor in formulations because higher loading leads to lower amount of NPs for a given dose. With respect to the amount of DT initially used (5 $\%$ and $10 \% \mathrm{w} / \mathrm{w}$ ), EE \% was found to decrease as the DT concentration increased. This means that the maximum amount which can be entrapped in the polymer matrix i.e. miscibility of the polymer with the active substance is limited [14]. The remaining drug may migrate to the surrounding emulsifier aqueous phase. If the surfactant used to stabilize the emulsion is present at a concentration higher than the critical micelle concentration, surfactant micelles can solubilize the drug, which may reduce 
encapsulation efficiency [33]. The findings obtained in this study support this hypothesis. As a result, formulations with a high EE \% were produced and the EE \% was decreased by increasing the amount of agent.

Two main release mechanisms associated with drug release from PLGA nanoparticle systems are diffusion and degradation/erosion. It has been reported that drug release rate is initially controlled by diffusion followed by degredation/erosion [22]. There seems to be an inverse relationship between amount of drug released and particle size. It was reported previously that large microspheres degrade faster than small microspheres. This is probably due to the increased accumulation of acidic products during polymer hydrolysis in large microspheres where hydrolysis starts immediately in PLGA systems.

Further catalysis of hydrolysis by the acids produced during the initial hydrolysis ie the autocatalytic process leads to a more rapid degradation at the center of the PLGA matrix than from the surface. This effect becomes more pronounced as the size of the nanoparticle system increases [22]. Alp-10 formulation with a larger particle size probably degrades relatively faster than Alp-5 formulation, leading to a higher release. A biphasic profile consisting of a rapid phase followed by a slow release phase was observed for DT from PLGA NPs.

An Excel add-in DDSolver program which allows modeling of dissolution data was designed by researchers to reduce computation time and eliminate computational errors [18]. Higuchi model was the most appropriate kinetic model for DT release from Alp-5 formulation while the best fit of Alp-10 formulation was to the KorsmeyerPeppas model. This difference may be attributed to different loading efficiencies (\% EE) and localization of the active agent in different regions within the polymer.

The disappearance of endothermic DT peak in DSC thermograms of all PLGA NPs indicates incorporation of DT, homogenous matrix formation and amorphous structure [13]. The characteristic melting peak of DT was seen in the thermogram of physical mixture which can also be considered as an indicator of the amorphous state of DT in the formulations [23].

The technique of XRD is a well-defined analytical method frequently used in research because it clarifies molecular structure of nanoparticles, examines crystal state, investigates polymorphism and also provides information about stability [18]. The absence of DT crystal peaks in XRD profiles of all prepared NPs demonstrated amorphous nanoparticle formation and DT dispersion in polymeric matrix at the molecular level which may be due to the dilution effect [42]. Disappearance of DT peaks in XRD profiles of NPs suggest absence of high superficial adsorption and occurence of incorporation $[20,23]$.

Infrared spectroscopy analysis is important and is used frequently to determine the chemical composition and regulation of binding of components to homo-polymer, co-polymer, polymer composite, polymeric materials and nanotechnology [44]. It was observed that the characteristic DT peaks disappeared or appeared with very low intensity in the spectra of PLGA nanoparticles prepared. This indicates that DT was molecularly dispersed and incorporated into the polymeric structure, which is consistent with the results from DSC and XRD [23].

Physicochemical properties of nanoparticles, interaction of active ingredients with polymers/additives and molecular mobility can be determined by NMR analysis [49]. When the results of the analysis were evaluated, it was seen that there was no significant difference between the spectra of empty formulation and that of pure PLGA. This shows clearly that there was no structural change due to the effect of other substances or preparation conditions. Lowered DT peaks at 7-8 ppm in the spectra of Alp-5 and Alp-10 PLGA NPs suggest DT incorporation into PLGA polymer, as well as molecular distribution of DT in the polymeric matrix $[13,20,23]$.

In this study, time and dose-dependent MTT experiments were performed to detect living cells depending on the degree of activation of the signaling cells produced [13]. The PLGA NPS are the most preferred delivery systems due to their sustainability, degradability and better loading capacity. It has been reported previously that no significant cytotoxicity is observed with PLGA even at high concentrations [24]. In this study, the high $\mathrm{IC}_{50}$ (> $1250 \mu \mathrm{g} / \mathrm{mL}$ after $72 \mathrm{~h}$ incubation) determined for the empty formulation without DT shows the safety of the polymer and other excipients used for NP preparation. Literature survey showed only one study on the cytotoxicity of DT which reported high toxicity depending on time and concentration. İncreased cytotoxicity due to application of DT alone to the wells was observed in a previous study performed by the present research group [13]. However, PLGA NPs containing DT demonstrated $55 \%$ cell viability even at the highest concentration. Thus, PLGA NPs were 
able to prevent cytotoxicity at high DT concentrations.

\section{CONCLUSION}

This study shows that DT loaded PLGA NPs can be prepared successfully by double emulsion solvent evaporation method. The particle size of the NPs obtained were in the nanometer range and remained constant in the short-term GI stability testing. The nanoparticle formulation did not show significant cytotoxicity at dose- and time-dependent considerations. Thus, it is considered appropriate for drug delivery purposes. The DT-loaded PLGA NPs are stable and represent a promising system for sustained and controlled delivery of DT.

\section{DECLARATIONS}

\section{Acknowledgement}

This study was financed by Anadolu University Scientific Research Project Foundation (no. 1708S471). The authors would like to thank Abdi İbrahim (İstanbul, Turkey) for kindly providing DT. Faculty of Science is acknowledged for XRD, DOPNALAB Faculty of Pharmacy for FTIR and ${ }^{1} \mathrm{H}$-NMR and AUBIBAM for SEM analyses. We also thank University of Seville, Faculty of Pharmacy, Department of Pharmacy and Pharmaceutical Technology for making available their facilities for this work.

\section{Conflict of Interest}

No conflict of interest associated with this work.

\section{Contribution of Authors}

The authors declare that this work was done by the authors named in this article and all liabilities pertaining to claims relating to the content of this article will be borne by them.

\section{REFERENCES}

1. Breivik H, Collett B, Ventafridda V. Survey of Chronic Pain in Europe: Prevalence, Impact on Daily Life, and Treatment. Eur J Pain 2006; 10: 287-333.

2. Romano CL, Romano D, Lacerenza M. Antineuropathic and Antinociceptive Drugs Combination in Patients with Chronic Low Back Pain: A Systematic Review. Pain Res Treat 2012: 154781.

3. Jin J. Nonsteroidal Anti-inflammatory Drugs. JAMA 2015; 314 (10): 1084

4. Mainardi F, Maggioni F, Pezzola D, Zava D, Zanchiny G. Dexketoprofen Trometamol in the Acute Treatment of
Migraine Attack: A Phase II, Randomized, Double-Blind, Crossover, Placebo-Controlled, Dose Optimization Study. J Pain 2014; 15(4): 388-394.

5. Öztürk AA, Yenilmez E, Yazan Y. Development and Validation of High Performance Liquid Chromatography (HPLC) Modified Method for Dexketoprofen Trometamol. Eur Int J Sci Tech 2017; 6(5): 33-41.

6. Kapse SV, Gaikwad RV, Samad A, Devarajan PV. Self Nanoprecipitating Preconcentrate of Tamoxifen Citrate for Enhanced Bioavailability. Int J Pharm 2012; 429: 104-112.

7. Kumari A, Yadav SK, Yadav SC. Biodegradable Polymeric Nanoparticles Based Drug Delivery Systems. Colloids Surf B Biointerfaces 2010; 75: 1-18.

8. Hines DJ, Kaplan DL. Poly (Lactic-Co-Glycolic Acid) Controlled Release Systems: Experimental and Modeling Insights. Crit Rev Ther Drug Carrier Syst 2013; 30(3): 257-276.

9. Derman S, Kızılbey K, Akdeste ZM. Polymeric Nanoparticles. J Eng Nat Sci 2013; 31: 107-120.

10. Iqbal M, Zafar N, Fessi H, Elaissari A. Double Emulsion Solvent Evaporation Techniques Used for Drug Encapsulation. Int J Pharm 2015; 496: 173-190.

11. Yong $H$, Yonglin $W, L i n Z, Y u L Y$, Yongjun Li, Lingyun $S$, Feng $H$, Zhirong $Z$, Hui C. Preparation Method of Dexketoprofen Trometamol Double-Layer SustainedRelease Tablets. 2012; Patent Number: CN 102813638 A.

12. Yong $H$, Yonglin $W$, Lingyun $S$, Lin $Z$, Feng $H$, Yanyu $L$, Yongjun L, Aimin W, Shanggao L, Xiaozhong F, Wen $Z$, Zhirong Z, Hui C. Dexketoprofen Trometamol QuickRelease/Sustained-Release Double-Layer Tablet and Preparation Method Thereof. 2014; Patent Number: CN 103655504 A.

13. Öztürk $A A$, Yenilmez $E$, Arslan $R$, Şenel B, Yazan $Y$. Dexketoprofen Trometamol-Loaded Kollidon $\Theta S R$ and Eudragit@ RS 100 Polymeric Nanoparticles: Formulation and In Vitro-In Vivo Evaluation. Lat Am J Pharm 2017; 36(11): 2153-2165.

14. Martín-Banderas L, Alvarez-Fuentes J, Duran-Lobato M, Prados J, Melguizo C, Fernandez-Arvelo M, Holgado MaA. Cannabinoid Derivate-Loaded PLGA Nanocarriers for Oral Administration: Formulation, Characterization, and Cytotoxicity Studies. Int J Nanomed 2012; 7: 57935806.

15. Abdelwahed W, Degobert G, Stainmesse S, Fessi $H$. Freeze-drying of Nanoparticles: Formulation, Process and Storage Considerations. Adv Drug Deliv Rev 2006; 58(15):1688-1713

16. Bhusari VK, Dhaneshwar SR. Development of a Validated Stability-Indicating HPLC Assay Method for Dexketoprofen Trometamol. Int J Pharm Pharm Sci 2012; 4 (1): 321-326.

17. Obitte NC, Chukwu A, Onyishi IV. The Use of a $\mathrm{pH}$ Dependent and Non pH-Dependent Natural Hydrophobic Biopolymer (Landolphia owariensis latex) as Capsule Coating Agents in In Vitro Controlled 
Release of Metronidazole for Possible Colon Targeted Delivery. Int J Appl Res Nat Prod 2010; 3(1): 1-17.

18. Zhang $Y$, Huo $M$, Zhou J, Zou A, Li W, Yao C, Xie $S$. DDSolver: an Add-In Program for Modeling and Comparison of Drug Dissolution Profiles. The AAPS J 2010; 12: 263-271.

19. Gencer S, Cebeci A, Irmak-Yazicioglu MB. Silencing of the MMP-3 Gene by siRNA Transfection in Gastric Cancer AGS Cells. J Gastrointestin Liver Dis 2010; 20: 19-26

20. Öztürk $A A$, Martin Banderas L, Cayero Otero MD, Yenilmez E, Yazan Y. New Approach to Hypertension Treatment: Carvediol-Loaded PLGA Nanoparticles, Preparation, In Vitro Characterization and Gastrointestinal Stability. Lat Am J Pharm. 2018; 37(9): 1730-1741

21. Palacio J, Orozco VH, Lopez BL. Effect of the Molecular Weight on the Physicochemical Properties of Poly(Lactic
Acid) Nanoparticles and on the Amount of Ovalbumin Adsorption. J Braz Chem Soc 2011; 22(12): 2304-2311.

22. Fredenberg S, Wahlgren M, Reslow M, Axelsson A. The Mechanisms of Drug Release in Poly(Lactic-Co-Glycolic Acid)-Based Drug Delivery Systems- A Review. Int $J$ Pharm 2011; 15(1-2): 34-52.

23. Öztürk $A A$, Güven UM, Yenilmez E, Şenel B. Effects of Different Derivatives of Eudragit Polymer on Entrapment Efficiency, In Vitro Dissolution, Release Kinetics and Cell Viability Results on Extended Release Flurbiprofen Loaded Nanomedicines. Lat Am J Pharm 2018; 37(10): 1981-1992.

24. Jain DS, Athawale RB, Bajaj AN. Unraveling the Cytotoxic Potential of Temozolomide Loaded into PLGA Nanoparticles. DARU J Pharm Sci 2014; 22(1): 18. doi:10.1186/2008-2231-22-18. 